Article

\title{
The DN-6 Neutron Diffractometer for High-Pressure Research at Half a Megabar Scale
}

\author{
Denis Kozlenko, Sergey Kichanov * (D), Evgenii Lukin and Boris Savenko \\ Frank Laboratory of Neutron Physics, JINR, 141980 Dubna, Russia; denk@nf.jinr.ru (D.K.); lukin@jinr.ru (E.L.); \\ savenko@nf.jinr.ru (B.S.) \\ * Correspondence: ekich@nf.jinr.ru; Tel.: +7-49-6216-2112
}

Received: 18 July 2018; Accepted: 18 August 2018; Published: 20 August 2018

\begin{abstract}
A neutron diffractometer DN-6 at the IBR-2 high-flux reactor is used for the studies of crystal and magnetic structure of powder materials under high pressure in a wide temperature range. The high neutron flux on the sample due to a parabolic focusing section of a neutron guide and wide solid angle of the detector system enables neutron diffraction experiments with extraordinarily small volumes (about $0.01 \mathrm{~mm}^{3}$ ) of studied samples. The diffractometer is equipped with high-pressure cells with sapphire and diamond anvils, which allow pressures of up to $50 \mathrm{GPa}$ to be reached. The technical design, main parameters and current capabilities of the diffractometer are described. A brief overview of recently obtained results is given.
\end{abstract}

Keywords: neutron diffraction; high pressure; crystal and magnetic structure

\section{Introduction}

The dramatic progress in research under extreme conditions has been driven by the discovery of a great number of novel and interesting phenomena in condensed matter physics and material science, chemistry, and geophysics and planetary research [1]. In comparison to other experimental methods, the application of high pressure is a direct method for controlling changes in physical properties by means of variation of interatomic distances and angles, molecular conformations, or energy balance between different competing interactions [2].

Currently, multi-megabar high-pressure experiments are realized using high-brilliance third-generation synchrotron radiation sources $[3,4]$. Neutron diffraction has many advantages over X-ray techniques for studying the crystal structure of materials containing light atoms like hydrogen and oxygen and, especially, for studying the magnetic structure of materials [5-8]. However, the evolution of high-pressure neutron diffraction techniques has been seriously restricted by the drastically low intensities of neutron sources (many orders of magnitude lower) in comparison with synchrotron radiation ones. As a result, neutron diffraction techniques for studies at high pressures of up to $10 \mathrm{GPa}$ and above have been developed quite recently, and the corresponding experimental possibilities are only available in a few advanced neutron scattering research centers in the world, including the DISK diffractometer [9] at the IR-8 research reactor in National Research Center "Kurchatov Institute" (Moscow, Russia); the PEARL diffractometer [10] at ISIS RAL (UK); the G6.1 diffractometer [6] at LLB (Saclay, France); the high-pressure set-up [11] for HRPT diffractometer at the SINQ neutron spallation source (Paul Scherer Institute, Villigen, Switzerland); the high-pressure opportunities [12] on D20 at ILL (Grenoble, France); the HiPPO diffractometer [13] at the Los Alamos Neutron Science Center (Los Alamos, NM, USA); the PLANET diffractometer [14] at J-PARC (Ibaraki, Japan); the SNAP diffractometer $[15,16]$ at SNS spallation neutron source (Oak Ridge National Laboratory, Oak Ridge, TN, USA). 
One should note that development of techniques for neutron diffraction experiments at the extended pressure range beyond $20 \mathrm{GPa}$ is still in the state-of-art stage, and so far, only a few research examples, mostly for model systems with large neutron scattering lengths (or large magnetic moment values) have been reported at such a pressure scale [6,17-19].

The Frank Laboratory of Neuron Physics at JINR (Dubna, Russia), the basic facility of which is the IBR-2 high-flux pulsed reactor [20], has more than twenty years of experience in the development of neutron scattering methods at high pressure $[17,21-23]$. The high-pressure cells with sapphire anvils opposite are used on a specialized neutron diffractometer DN-12 for micro-sample studies [21]. The available pressure range is restricted to 6-8 GPa. However, many challenging phenomena in condensed matter physics require a higher-pressure range above $10 \mathrm{GPa}$, which cannot be obtained on the DN-12 diffractometer due to the incident neutron flux limitation caused by the reactor moderator geometry in the beamline layout. As a more advanced solution, a new high-brilliance diffractometer DN-6, combining higher incident neutron flux and wide aperture of the detector system, has been developed in recent years. The present paper describes the current state of the DN-6 diffractometer for studies of atomic and magnetic structure of materials under extreme conditions using sapphire and diamond anvil cells at a pressure range of about half a megabar.

\section{The Design and Main Parameters of the DN-6 Diffractometer}

The DN-6 neutron diffractometer for high-pressure research is located on the $6 \mathrm{~b}$ beamline of the IBR-2 high-flux pulsed reactor (Figure 1).

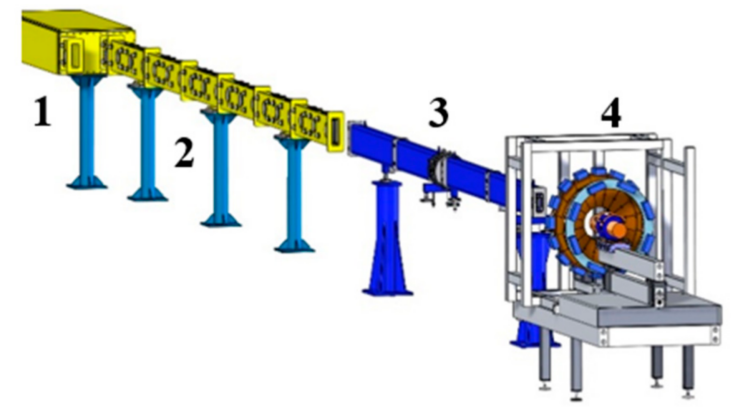

(a)

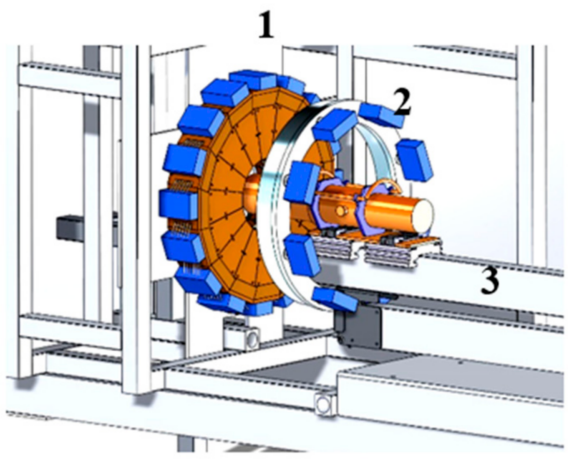

(b)

Figure 1. (a) The layout of the DN-6 diffractometer at the IBR-2 high-flux reactor. The neutron beam splitter (1), curved neutron guide (2), and parabolic neutron focusing system (3) are shown. The location of detector and sample environment systems (4) of the DN-6 diffractometer is marked. (b) Enlarged schematic layout of detector and sample environment systems of the DN-6 diffractometer. The 90-deg. scattering angle detector section (1), the low scattering angle detector section (2), the horizontal cryostat (3) and sample and high-pressure cell holders fixed on the movable slider are shown. The diffractometer components are mounted on a mechanical support cage.

The neutron beam is formed by means of a three-section neutron guide. The first section is a neutron beam splitter, dividing the incident neutron beam into two parts for the DN-6 and the neighboring Real-Time Neutron diffractometer (RTD) (Frank Laboratory of Neutron Physics, Dubna, Russia) on the 6a beamline. The continuation of the neutron guide is a twenty-meter curved part with a $\mathrm{m}=1$ coating and a total radius of curvature of $1860 \mathrm{~m}$. The dimensions of the neutron beam after this section are $15 \times 165 \mathrm{~mm}$. Options for different neutron focusing systems for the end part of the neutron guide were considered [24]. Finally, the parabolic-shaped system with vertical focusing and a $\mathrm{m}=3$ coating was manufactured by SwissNeutronics (Klingnau, Switzerland), and installed as the third ending section of the neutron guide. The focused beam with dimensions of $10 \times 10 \mathrm{~mm}$ is 
located at a distance of $870 \mathrm{~mm}$ from the end of the section (Figure 2a). The new focusing section of the neutron guide increases the total neutron flux on the sample on average by about 6 times (Figure $2 b$ ). The total length of the beamline from source to sample position is $30.5 \mathrm{~m}$. As an example, the neutron diffraction pattern of the standard powder sample $\mathrm{LaB}_{6}$ [25] is presented in Figure 2c. The instrument and performance parameters of the DN-6 diffractometer are listed in Table 1.

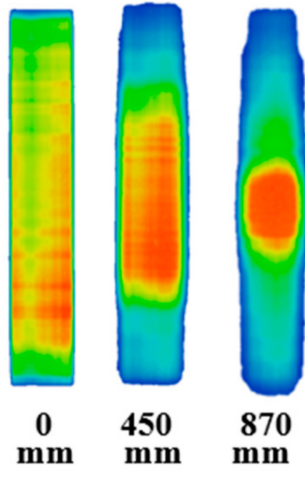

(a)

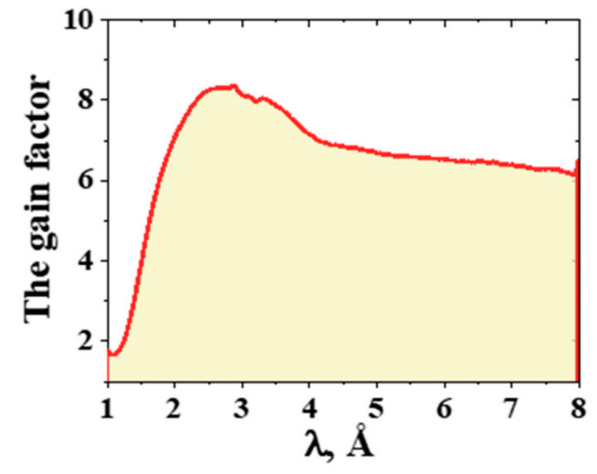

(b)

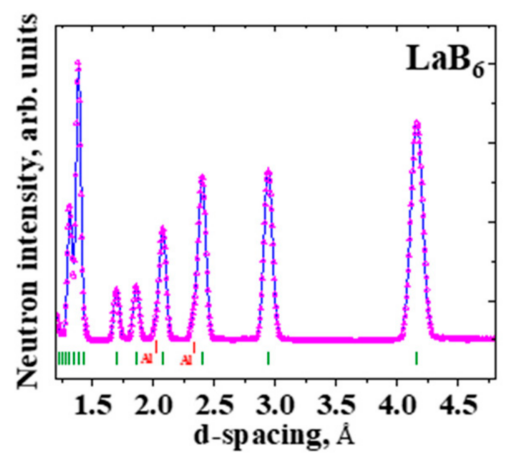

(c)

Figure 2. (a) The profiles of the neutron beam of $6 \mathrm{~b}$ beamline obtained at different distances from the neutron focusing section output. The coloring scheme shows neutron intensity distribution from low (blue) to high (red). (b) The spectral distribution of the gain factor of the incident neutron beam flux after the focusing section related to one of the old straight section of the neutron guide. (c) The neutron diffraction pattern of $\mathrm{LaB}_{6}$ processed by the Rietveld method. The experimental points and calculated profiles are shown. Ticks below represent calculated positions of the nuclear peaks of the cubic phase of $\mathrm{LaB}_{6}$ at ambient conditions. The shoulder peaks from aluminum container are marked.

The pulse regime of the IBR-2 reactor operation provides neutron diffraction measurements in the DN-6 diffractometer using a time-of-flight (TOF) mode. There are two detector sections with a circular form installed at different scattering angles in the DN-6 diffractometer.

Table 1. The technical parameters of the DN-6 diffractometer and the available experimental capabilities.

\begin{tabular}{cc}
\hline $\begin{array}{c}\text { The Neutron Flux on Sample Place } \\
\text { (measured by gold foils activation method) }\end{array}$ & $\sim 3.5 \times 10^{7} \mathrm{n} / \mathrm{cm}^{2} / \mathrm{s}$ \\
\hline The Characteristic TOF Distance & $30.5 \mathrm{~m}$ \\
\hline $\begin{array}{c}\text { The Achievable D-Spacing Range } \\
\text { at scattering angle } 2 \theta=90^{\circ}:\end{array}$ & $0.5-5.7 \AA$ \\
at scattering angle $2 \theta=42^{\circ}:$ & $1.8-11.2 \AA$ \\
\hline Resolution $\Delta d / d$ (for the $d=2$ A) \\
$\quad \begin{array}{c}\text { at } 2 \theta=90^{\circ}: \\
\text { at } 2 \theta=42^{\circ}:\end{array}$ & 0.025 \\
\hline $\begin{array}{c}\text { The Typical Data Collection Time } \\
\text { Sample under ambient conditions, } V \sim 50 \mathrm{~mm}^{3}\end{array}$ & 0.030 \\
\hline $\begin{array}{c}\text { Sample in high-pressure cell with sapphire anvils, } V \sim 1 \mathrm{~mm}^{3} \\
\text { Sample in high-pressure cell with diamond anvils, } V \sim 0.01 \mathrm{~mm}^{3}\end{array}$ & $0.1 \mathrm{~h}$ \\
\hline $\begin{array}{c}\text { The Available Pressure Range in Experiments } \\
\text { high-pressure cell with sapphire anvils } \\
\text { high-pressure cell with diamond anvils }\end{array}$ & $20-40 \mathrm{~h}$ \\
\hline $\begin{array}{c}\text { The Available Temperature Range } \\
\text { The cryostat based on a closed-cycle helium refrigerator }\end{array}$ & $12 \mathrm{GPa}$ \\
\hline
\end{tabular}


The first section (Figure 3a) is composed of $96{ }^{3} \mathrm{He}$-filled separate detector counters, arranged in the form of six rings of 16 detectors each with radius of $350 \mathrm{~mm}$ (Figure $3 \mathrm{~b}$ ).

The detector system provides neutron registration in the range of scattering angles of $87-93^{\circ}$. The neutron diffraction patterns are obtained by summation of spectra from each detector element with the relevant correction for the scattering angle variation. The second detector section also has a circular form, but it has another technical design, with the unified ${ }^{3} \mathrm{He}$ gas filling of the whole section volume, which is described in detail in [26]. It collects the neutron diffraction data in the lower scattering angle range of $35-43^{\circ}$. Both of the detector sections are placed in boron-containing polyethylene shielding (Figure 3a) to improve the background conditions in experiments. The detectors' electronics are based on the MPD-32 module [27,28], which can provide data collection for 240 independent detector elements. The software modules SONIX+ [29] provide the control procedures for the automatization of experiments and visualization of neutron diffraction data.

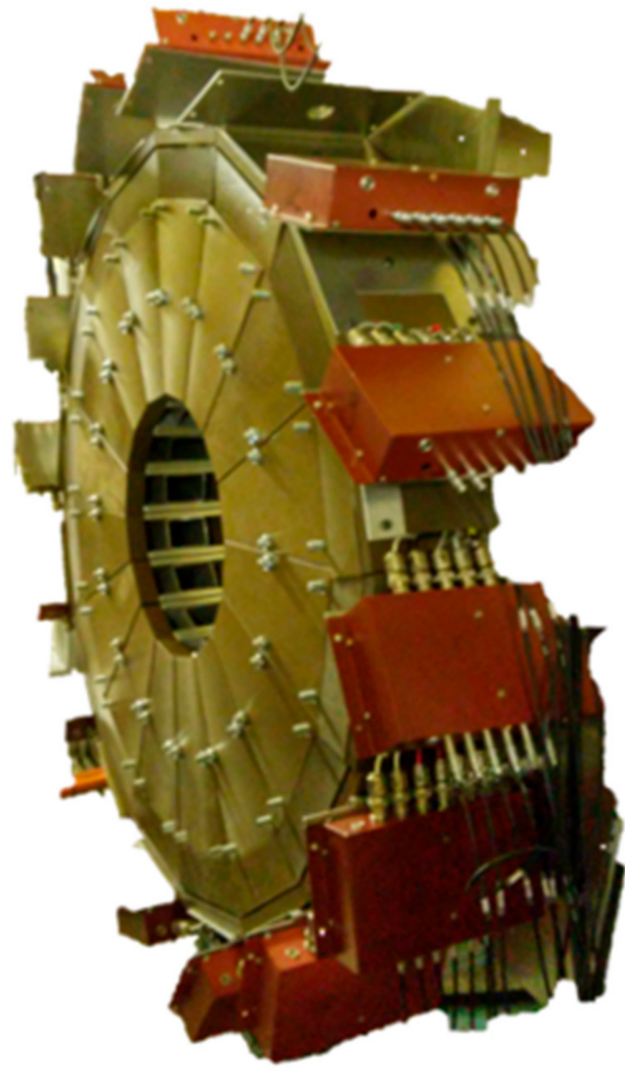

(a)

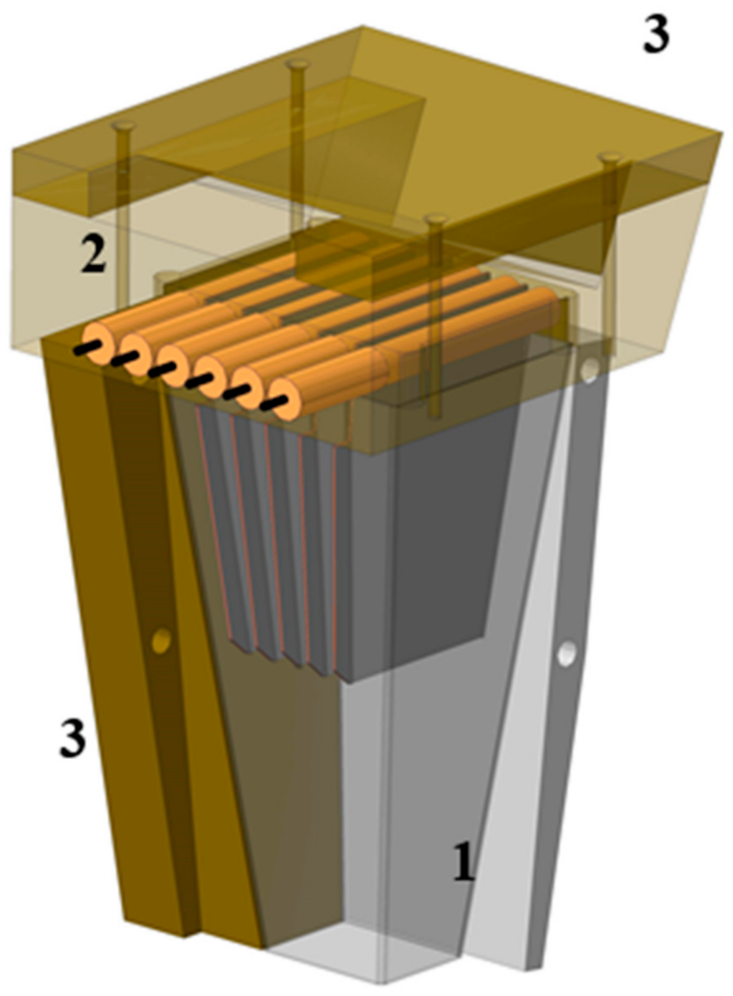

(b)

Figure 3. (a) The 90-degree detector section of the DN-6 diffractometer. The detectors are located in boron-polyethylene covering for background protection and consist of sixteen sectoral collimators modules and detector blocks. The red boxes are pre-amplifier modules of neutron counters. (b) The layout of the sectoral detector module. The cadmium inner collimator unit (1), placement of the six neutron counters (2), and the surrounding shielding of boron-containing polyethylene material (3) are shown.

The horizontal cryostat [30] based on a closed-cycle helium refrigerator is used for low-temperature experiments in the range 5-320 K. The design of the cryostat provides the possibility of cooling high-pressure cells with different constructions. 


\section{The High-Pressure Equipment of the DN-6}

Various types of the compact high-pressure cells are used for the experiments using the DN-6 diffractometer (Figure 4).

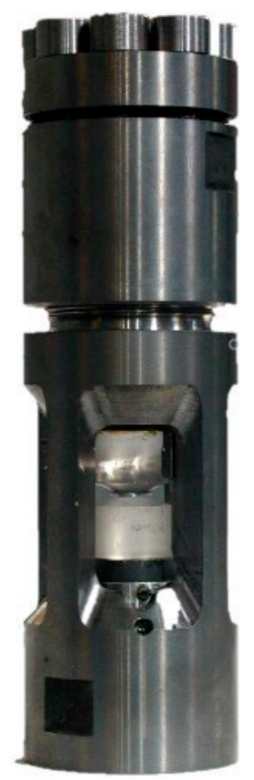

(a)

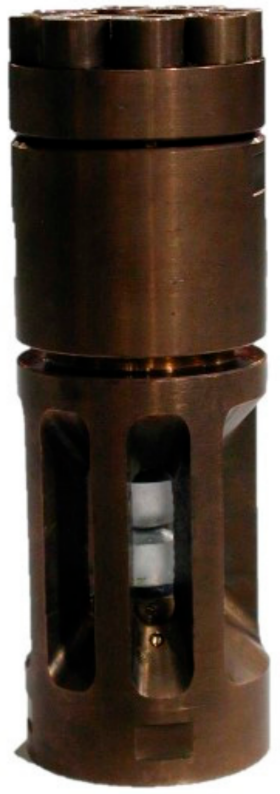

(b)

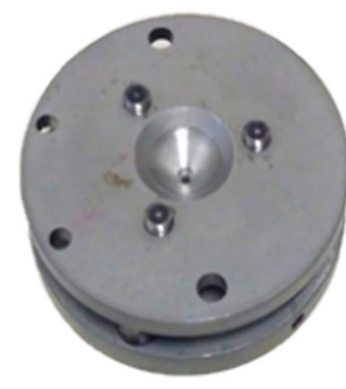

(c)

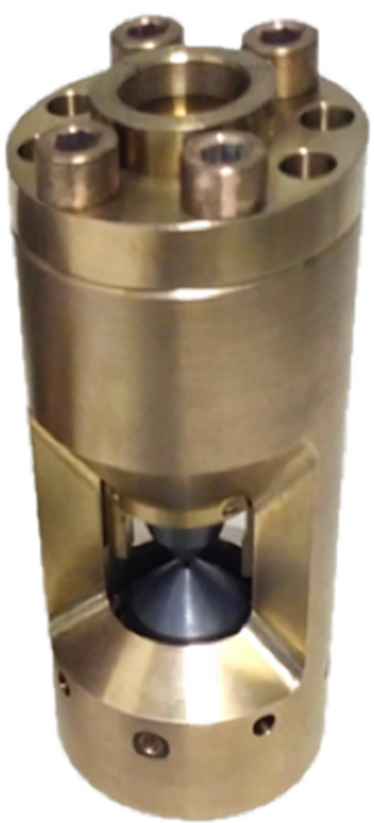

(d)

Figure 4. The high-pressure cells used on DN-6 diffractometer: (a) the steel high-pressure cell with sapphire anvils; (b) the beryllium-bronze six-column high-pressure cell with sapphire anvils; (c) standard Almax Plate diamond anvils cell (DAC); (d) wide-aperture DAC.

High-pressure cells with sapphire anvils $[17,22]$ are applied for routine experiments in the pressure range up to $12 \mathrm{GPa}$ in the temperature range $5-320 \mathrm{~K}$. Their design (Figure $4 \mathrm{a}, \mathrm{b}$ ) provides wide-aperture side windows for the scattered neutrons that are compatible with the geometry of the detector system. To achieve a quasi-hydrostatic pressure distribution on the sample surface, hemispherical holes are made in the center of the anvil culets. The typical sample volume in the high-pressure cell with sapphire anvils is about $2 \mathrm{~mm}^{3}$, and the relevant data collection time is about $2-4 \mathrm{~h}$. The reduction of the culet size of anvils and the corresponding sample volume to $0.5 \mathrm{~mm}^{3}$ makes it possible to achieve maximum pressures of about 11-12 GPa.

For a significant expansion of the pressure range in diffraction experiments, high-pressure cells with diamond anvils are also applied on the DN-6 diffractometer. There are several different types of high-pressure cells, including plate DAC cells manufactured by Almax easyLab (Diksmuide, Belgium) and specially designed wide-aperture high-pressure cells (RNC "Kurchatov Institute" -FLNP JINR); Figure 4c,d, respectively. The application of diamond anvils with an anvil culet size of about $0.45-0.5 \mathrm{~mm}$ and a sample volume of about $0.01 \mathrm{~mm}^{3}$ makes it possible to achieve pressures up to about 40-50 GPa [31]. The typical data collection times extend to 20-40 h.

The pressure value inside the high-pressure cells described above is determined by the ruby fluorescence technique [32].

\section{An Overview of the Scientific Research at the DN-6 Diffractometer}

In recent years, several studies have focused on performing pressure-induced modifications of the crystal structure and magnetic order in different powder materials. 
A pressure-induced structural phase transition was observed in double perovskite $\mathrm{Pb}_{2} \mathrm{MgWO}_{6}$ from the orthorhombic to cubic phase at high pressures above $0.9 \mathrm{GPa}$, corresponding to an antiferroelectric to paraelectric phase transition [33].

The structural and magnetic properties of the siderite $\mathrm{FeCO}_{3}$ have been studied at high pressures of up to $7.5 \mathrm{GPa}$, complemented by the ab-initio calculations [34]. An unexpectedly large pressure coefficient of the Néel temperature and reduction of the ordered iron magnetic moments were revealed.

The crystal and magnetic structures of nanostructured manganites [35] have been studied at high pressures. At ambient pressure, the ferromagnetic (FM) phase coexists with an A-type antiferromagnetic (AFM) phase. Under high pressure, the volume fraction of AFM phase increases, while FM is gradually suppressed.

At pressures $P \sim 1.5 \mathrm{GPa}$ and temperatures below $T_{N} \sim 110 \mathrm{~K}$, the appearance of a new A-type antiferromagnetic AFM phase in bulk manganite $\mathrm{La}_{0.7} \mathrm{Sr}_{0.3} \mathrm{Mn}_{0.83} \mathrm{Nb}_{0.17} \mathrm{O}_{3}$ was observed [36].

The magnetic properties of doped ferrite $\mathrm{Zn}_{0.3} \mathrm{Cu}_{0.7} \mathrm{Fe}_{1.5} \mathrm{Ga}_{0.5} \mathrm{O}_{4}$ have been studied at high pressures [37]. A gradual suppression of the magnetic moments of iron ions at different crystallographic sites was found at ambient temperature.

The magnetic structure of the $\mathrm{DyGe}_{2.85}$ material synthesized under high-pressure conditions was studied [38]. The formation of an antiferromagnetic spiral ordering of dysprosium magnetic moments was revealed.

The structural and magnetic properties of the eskolaite $\mathrm{Cr}_{2} \mathrm{O}_{3}$ have been studied at high pressures of up to $35 \mathrm{GPa}$ [31]. The AFM ground state magnetoelectrically active in external magnetic fields was found to be stable in the whole studied pressure range (Figure 5), not confirming a magnetic phase transition that had previously been assumed from optical second-order harmonic generation experiments. The pressure coefficient of the Néel temperature was accurately determined.

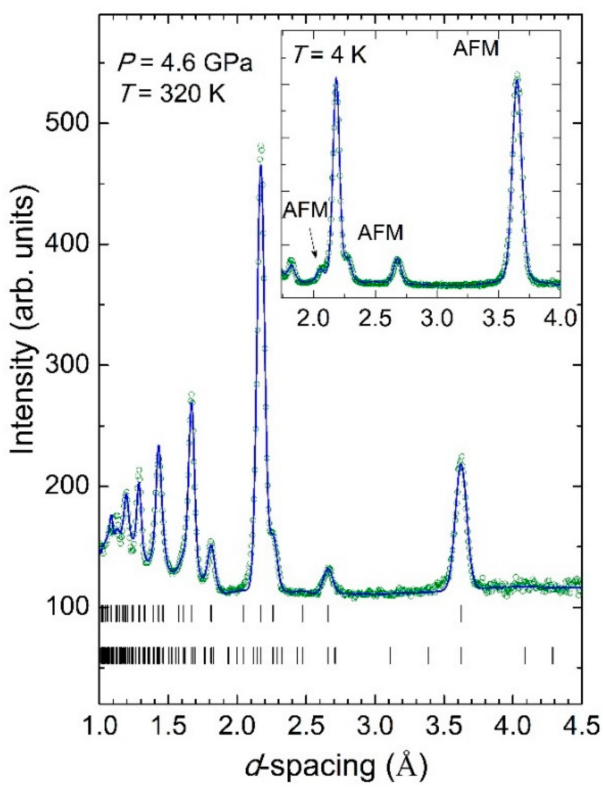

(a)

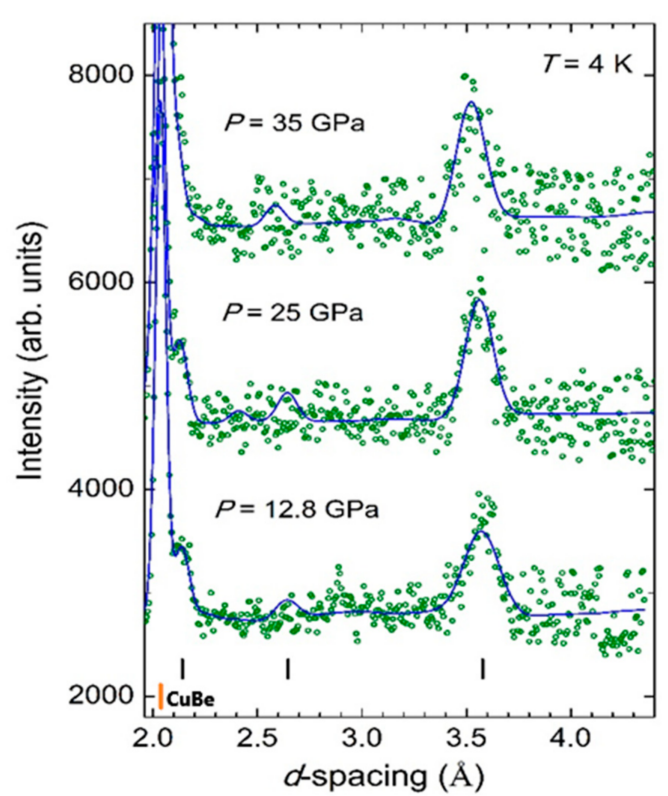

(b)

Figure 5. The neutron diffraction patterns of $\mathrm{Cr}_{2} \mathrm{O}_{3}$, measured at $P=4.6 \mathrm{GPa}, T=320$ and $4 \mathrm{~K}$ in sapphire anvil cell (a) and measured at $P=12.8,25$ and $35 \mathrm{GPa}$ and $T=4 \mathrm{~K}$ in the diamond anvil cell (b), fitted by the Rietveld method. The experimental points and calculated profiles are shown. The ticks below represent the calculated positions of the nuclear peaks (upper row) and magnetic peaks (lower row). In the right panel, the positions of the nuclear and magnetic peaks coincide. In addition, a peak position for the CuBe gasket is also shown. 
Previously, high-pressure experiments using compact diamond anvil cells on a comparable pressure scale had mostly been reported for a restricted number of model systems, either containing atoms with large neutron scattering lengths, like $\mathrm{D}_{2}[18,39]$ and $\mathrm{D}_{2} \mathrm{O}$ [40], or with large magnetic moments, like Gd [6,19]. The advantage of the DN-6 diffractometer is that it can be routinely used for studies on a broad range of powder systems with average neutron scattering lengths and magnetic moments. For instance, the ordered magnetic moment values of $\mathrm{Cr}^{3+}$ ions in $\mathrm{Cr}_{2} \mathrm{O}_{3}$ at low temperature are just about $3 \mu_{\mathrm{B}}$ [31], typical for many transition metal oxides containing $\mathrm{Cr}, \mathrm{Mn}$, Fe ions, and it is much lower in comparison with the most of the relevant values of the rare-earth elements.

\section{Conclusions}

The DN-6 diffractometer for high-pressure research provides possibilities for routine studies of broad classes of powder materials with ordinary neutron scattering lengths and average magnetic moment values over a significantly extended high-pressure range (experimentally achieved, currently, at up to $35 \mathrm{GPa}$, and potentially possible at up to $50 \mathrm{GPa}$ ) and low temperature. The appropriate configuration of the neutron guide system and large solid angle multi-element detector system combined with low background shielding and a set of high-pressure cells with diamond and sapphire anvils makes the parameters of the DN-6 diffractometer comparable with the most advanced dedicated instruments in the other leading neutron scattering centers.

Author Contributions: Conceptualization, D.K. and B.S.; Methodology, D.K., S.K. and E.L.; Formal analysis, E.L.; Investigation, D.K. and S.K.; Methodology E.L., S.K. and B.S.; Project administration and supervision, D.K.; Writing-original draft, D.K. and S.K.

Funding: This research received no external funding.

Conflicts of Interest: The authors declare no conflict of interest.

\section{References}

1. Mao, H.-K.; Chen, B.; Chen, J.; Li, K.; Lin, J.-F.; Yang, W.; Zheng, H. Recent advances in high-pressure science and technology. Matter Radiat. Extremes 2016, 1, 59-75. [CrossRef]

2. Izyumov, Y.A. Magnetic Neutron Diffraction; Springer: Berlin, Germany, 1970; p. 598. ISBN 978-1-4684-0712-9.

3. Dubrovinsky, L.; Dubrovinskaia, N.; Prakapenka, V.B.; Abakumov, A.M. Implementation of micro-ball nanodiamond anvils for high-pressure studies above 6 Mbar. Nat. Commun. 2012, 3, 1163. [CrossRef] [PubMed]

4. Dubrovinskaia, N.; Dubrovinsky, L.; Solopova, N.A.; Abacumov, A.; Turner, S.; Hanfland, M.; Bykova, E.; Bykov, M.; Prescher, C.; Prakapenka, V.B.; et al. Terapascal static pressure generation with ultrahigh yield strength nanodiamond. Sci. Adv. 2016, 2, e1600341. [CrossRef] [PubMed]

5. Guthrie, M. Future directions in high-pressure neutron diffraction. J. Phys. Condens. Matter 2016, $27,153201$. [CrossRef] [PubMed]

6. Mirebeau, I. Magnetic neutron diffraction under high pressure. C. R. Phys. 2007, 8, 737-744. [CrossRef]

7. Klotz, S. Techniques in High Pressure Neutron Scattering; CRC Press: Boca Raton, FL, USA, 2016; p. 276. ISBN 9781138199217.

8. Belushkin, A.V.; Kozlenko, D.P.; Rogachev, A.V. Synchrotron and neutron-scattering methods for studies of properties of condensed matter: Competition or complementarity? J. Surf. Investig. X-ray Synchrotron Neutron Tech. 2011, 5, 828-855. [CrossRef]

9. Glazkov, V.P.; Naumov, I.V.; Somenkov, V.A.; Shilshtein, S.Sh. Superpositional many-detector system and neutron diffraction of microsamples. Nucl. Instrum. Methods Phys. Res. Sect. A 1988, 264, 367-374. [CrossRef]

10. Bull, C.L.; Funnell, N.P.; Tucker, M.G.; Hull, S.; Francis, D.J.; Marshall, W.G. PEARL: The high pressure neutron powder diffractometer at ISIS. High Press. Res. 2016, 36, 493-511. [CrossRef]

11. Klotz, S.; Strässle, T.; Rousse, G.; Hamel, G.; Pomjakushin, V. Angle-dispersive neutron diffraction under high pressure to 10 GPa. Appl. Phys. Lett. 2005, 86, 031917. [CrossRef]

12. Klotz, S.; Strässle, T.; Lebert, B.; d'Astuto, M.; Hansen, T. High pressure neutron diffraction to beyond $20 \mathrm{GPa}$ and below $1.8 \mathrm{~K}$ using Paris-Edinburgh load frames. High Press. Res. 2016, 36, 73-78. [CrossRef] 
13. Zhao, Y.; Zhang, J.; Xu, H.; Lokshin, K.A.; He, D.; Qian, J.; Pantea, C.; Daemen, L.L.; Vogel, S.C.; Ding, Y.; et al. High-pressure neutron diffraction studies at LANSCE. Appl. Phys. A 2010, 99, 585-599. [CrossRef]

14. Arima, H.; Hattori, T.; Komatsu, K.; Abe, J.; Utsumi, W.; Kagi, H.; Suzuki, A.; Suzuya, K.; Kamiyama, T.; Arai, M.; et al. Designing PLANET: Neutron beamline for high-pressure material science at J-PARC. J. Phys. Conf. Ser. 2010, 215, 012025. [CrossRef]

15. Iizuka, R.; Yagi, T.; Gotou, H.; Komatsu, K.; Kagi, H. An opposed-anvil-type apparatus with an optical window and a wide-angle aperture for neutron diffraction. High Press. Res. 2012, 32, 430-441. [CrossRef]

16. Boehler, R.; Molaison, J.J.; Haberl, B. Novel diamond cells for neutron diffraction using multi-carat CVD anvils. Rev. Sci. Instrum. 2017, 88, 083905. [CrossRef] [PubMed]

17. Somenkov, V.A. High-pressure neutron scattering over the ages. J. Phys. Condens. Matter 2005, 17, S2991-S3003. [CrossRef]

18. Glazkov, V.P.; Goncharenko, I.N.; Irodova, V.A.; Somenkov, V.A.; Shilstein, S.S.; Besedin, S.P.; Makarenko, I.N.; Stishov, S.M. Neutron diffraction study of molecular deuterium equation of state at high pressure. Z. Phys. Chem. 1989, 163, 509-514. [CrossRef]

19. Goncharenko, I.N.; Mirebeau, I.; Ochiai, A. Magnetic neutron diffraction under pressures up to 43 GPa. Study of the EuX and GdX compounds. Hyperfine Interact. 2000, 128, 225-244. [CrossRef]

20. Shvetsov, V.N. Neutron sources at the frank laboratory of neutron physics of the joint institute for nuclear research. Quantum Beam Sci. 2017, 1, 6. [CrossRef]

21. Aksenov, V.L.; Balagurov, A.M.; Glazkov, V.P.; Kozlenko, D.P.; Naumov, I.V.; Savenko, B.N.; Sheptyakov, D.V.; Somenkov, V.A.; Bulkin, A.P.; Kudryashev, V.A.; et al. DN-12 time-of-flight high-pressure neutron spectrometer for investigation of microsamples. Phys. B: Condens. Matter 1999, 265, 258-262. [CrossRef]

22. Kozlenko, D.P.; Savenko, B.N.; Glazkov, V.P.; Somenkov, V.A. Neutron scattering investigations of structure and dynamics of materials under high pressure at IBR-2 pulsed reactor. Neutron News 2005, 16, 13-15. [CrossRef]

23. Besedin, S.P.; Makarenko, I.N.; Stishov, S.M.; Glazkov, V.P.; Goncharenko, I.N.; Somenkov, V.A. Diamond anvil cells for neutron diffraction. High Press. Res. 1995, 14, 193-197. [CrossRef]

24. Belushkin, A.V.; Manoshin, S.A.; Kozlenko, D.P.; Kichanov, S.E. Modeling of the focusing device and the elliptical neutron guide for the DN-6 diffractometer at IBR-2 reactor. Nucl. Instrum. Methods Phys. Res. Sect. A 2018, 892, 48-52. [CrossRef]

25. Powder Line Position and Line Shape Standard for Powder Diffraction (Lanthanum Hexaboride Powder); SRM 660c; National Institute of Standards and Technology, Department of Commerce: Gaithersburg, MD, USA, 2014; p. 20899.

26. Belushkin, A.V.; Bogdzel, A.A.; Buzdavin, A.P.; Veleshki, S.I.; Zhuravlev, A.I.; Zhuravlev, V.V.; Kichanov, S.E.; Kozlenko, D.P.; Kulikov, S.A.; Levchanovskii, F.V.; et al. A multisectional annular thermal-neutron detector for the study of diffraction on microsamples in axial geometry. Phys. Part. Nuclei Lett. 2013, 10, 436-441. [CrossRef]

27. Churakov, A.V.; Belushkin, A.V.; Bogdzel, A.A.; Drozdov, V.A.; Kruglov, V.V.; Kulikov, S.A.; Levtchanovski, F.V.; Litvinenko, E.I.; Milkov, V.M.; Murashkevich, S.M.; et al. The detector systems of the IBR-2M spectrometers. J. Phys. Conf. Ser. 2018, 1021, 012021. [CrossRef]

28. Levchanovskiy, F.V.; Murashkevich, S.M. The data acquisition system for neutron spectrometry-A new approach and implementation. In Proceedings of the XXIV International Symposium Nuclear Electronics $\mathcal{E}$ Computing 2013; JINR: Dubna, Russia, 2013; p. 176. ISBN 978-5-9530-0374-2.

29. Kulikov, S.A.; Prikhodko, V.I. New generation of data acquisition and data storage systems of the IBR-2 reactor spectrometers complex. Phys. Part. Nucl. 2016, 47, 702-710. [CrossRef]

30. Chernikov, A.N.; Trofimov, V.N. Helium-3 adsorption refrigerator cooled with a closed-cycle cryocooler. J. Surf. Investig. X-ray Synchrotron Neutron Tech. 2014, 8, 956-960. [CrossRef]

31. Golosova, N.O.; Kozlenko, D.P.; Kichanov, S.E.; Lukin, E.V.; Liermann, H.-P.; Glazyrin, K.V.; Savenko, B.N. Structural and magnetic properties of $\mathrm{Cr}_{2} \mathrm{O}_{3}$ at high pressure. J. Alloys Compd. 2017, 722, 593-598. [CrossRef]

32. Mao, H.K.; Xu, J.; Bell, P.M. Calibration of the ruby pressure gauge to 800 kbar under quasi-hydrostatic conditions. J. Geophys. Res. 1986, 91, 4673-4676. [CrossRef]

33. Mekhdieva, R.Z.; Lukin, E.V.; Kichanov, S.E.; Kozlenko, D.P.; Jabarov, S.H.; Dang, T.N.; Mammadov, A.I.; Savenko, B.N. Structural aspects of the antiferroelectric-paraelectric phase transition in double perovskite $\mathrm{Pb} 2 \mathrm{MgWO6}$ at high pressures and temperatures. Phys. Solid State 2014, 56, 765-770. [CrossRef] 
34. Golosova, N.O.; Kozlenko, D.P.; Dubrovinsky, L.S.; Cerantola, V.; Bykov, M.; Bykova, E.; Kichanov, S.E.; Lukin, E.V.; Savenko, B.N.; Ponomareva, A.V.; et al. Magnetic and structural properties of $\mathrm{FeCO}_{3}$ at high pressures. Phys. Rev. B 2017, 96, 134405. [CrossRef]

35. Belozerova, N.M.; Kichanov, S.E.; Jirak, Z.; Kozlenko, D.P.; Kacenka, M.; Kaman, O.; Lukin, E.V.; Savenko, B.N. High pressure effects on the crystal and magnetic structure of nanostructured manganites $\mathrm{La}_{0.63} \mathrm{Sr}_{0.37} \mathrm{MnO}_{3}$ and $\mathrm{La}_{0.72} \mathrm{Sr}_{0.28} \mathrm{MnO}_{3}$. J. Alloys Compd. 2015, 646, 998-1003. [CrossRef]

36. Vu, M.T.; Kozlenko, D.P.; Kichanov, S.E.; Troyanchuk, I.O.; Lukin, E.V.; Khiem, L.H.; Savenko, B.N. Pressure induced antiferromagnetism in the manganite $\mathrm{La}_{0.7} \mathrm{Sr}_{0.3} \mathrm{Mn}_{0.83} \mathrm{Nb}_{0.17} \mathrm{O}_{3}$. J. Alloys Compd. 2016, 681, 527-531. [CrossRef]

37. Kozlenko, D.P.; Belozerova, N.M.; Ata-Allah, S.S.; Kichanov, S.E.; Yehia, M.; Hashhash, A.; Lukin, E.V.; Savenko, B.N. Neutron diffraction study of the pressure and temperature dependence of the crystal and magnetic structures of $\mathrm{Zn}_{0.3} \mathrm{Cu}_{0.7} \mathrm{Fe}_{1.5} \mathrm{Ga}_{0.5} \mathrm{O}_{4}$ polycrystalline ferrite. J. Magn. Magn. Mater. 2018, 449, 44-48. [CrossRef]

38. Salamatin, D.A.; Sidorov, V.A.; Kichanov, S.E.; Velichkov, A.; Salamatin, A.V.; Fomicheva, L.N.; Kozlenko, D.P.; Nikolaev, A.V.; Menzel, D.; Budzynski, M.; et al. Coexistence of charge density wave and incommensurate antiferromagnetism in the cubic phase of $\mathrm{DyGe}_{2.85}$ synthesised under high pressure. J. Alloys Compd. 2018, 755, 10-14. [CrossRef]

39. Sadykov, R.A.; Gruzinp, L.; Suhoparov, V.A. High pressure apparatus for neutron diffraction investigation of strongly compressible substances $\left(\mathrm{H}_{2}, \mathrm{D}_{2}\right.$, Ar). High Press. Res. 1995, 14, 199-202. [CrossRef]

40. Besson, J.M.; Pruzan, P.; Klotz, S.; Hamel, G.; Silvi, B.; Nelmes, R.J.; Loveday, J.S.; Wilson, R.M.; Hull, S. Interatomic distances in $\mathrm{D}_{2} \mathrm{O}$ VIII under high pressure from neutron scattering measurements to $10 \mathrm{GPa}$. AIP Conf. Proc. 1994, 309, 409-412. [CrossRef]

(C) 2018 by the authors. Licensee MDPI, Basel, Switzerland. This article is an open access article distributed under the terms and conditions of the Creative Commons Attribution (CC BY) license (http:/ / creativecommons.org/licenses/by/4.0/). 